\title{
Clinical Pathways of Postoperative Nursing Care for Women Undergoing Gynecological Operations at Port Said Hospitals
}

\author{
Assist.Prof.Manar Fathy Heeba, Dr. Elsayda Hamdy Nasr, Hanan Mohamed Ali Abou \\ Elsadat
}

Assistant prof of Maternity, Obstetric and Gynecological Nursing, Faculty of Nursing - Port said University, Lecturer of Maternity, Obstetric and Gynecological Nursing, Faculty of Nursing Port said University.

\begin{abstract}
Background: The aim of the present study is to investigate the effect of clinical pathways of postoperative nursing care for patients undergoing gynecologic operations on the postoperative outcome.Subjects and Methods: the study was conducted at Obstetric and Gynecologic Department. A total of 112 women undergoing gynecological operation (56 study group who received pre and postoperative care of clinical pathway, and 56 control group who received pre and postoperative routine care of the hospital).Results: The current study shows that patients underwent gynecological operation in the study group were significantly more likely to have no vomiting compared to those in the control group. Thus less than one fifth of them were in need to antiemetic compared to almost half in the control group. Concerning the level of pain experienced by patients during the postoperative period, the present result reveals that women in the study group experience less mean score compared to those in the control group, thus they showed lesser need for analgesia. Significant differences in the early oral intake, postoperative bowel mobility, hours to remove catheters and drains and length of stay were observed between present study and the control groups. Women's satisfaction related to the care provided was assessed in the present study group. The score given was mostly very good and excellent. Conclusion: Clinical pathway was effective in improving postoperative outcomes related to early ambulation, early oral intake, bowel mobility, hours to remove catheters and drains, short length of stay and patient satisfaction. Recommendations: The concept of clinical pathways should be applied in gynecologic operations to improve patient outcome and reduce postoperative complications.
\end{abstract}

Key words: Gynecological operations, clinical pathway nursing management. 


\section{INTRODUCTION}

A major challenge in healthcare is to incorporate innovations into routine clinical practice. Many innovations require an intensive, well-planned approach to become widely adopted. Although it usually takes many years to change well-established care, spontaneous spread of innovations can occur. The multimodal Enhanced Recovery After Surgery (ERAS) program aims at a more evidence-based perioperative care and challenges the change in routine clinical practice (Kehelt and Wilmore., 2008).

Clinical pathway, which comprises standardized procedures developed to guide evidence-based health care to avoid inconsistent practice, has been widely applied in various clinical disciplines (Kinsman et al., 2010). The aims of a clinical pathway are not only to promote quality of care and improve clinical outcome, but also to standardize important aspects of care as well as to avoid unnecessary delays and to reduce costs (Seehusen, 2010).

Implementation of an Enhanced Recovery Pathways (ERP) protocol is associated with decreased length of stay, a decrease in rates of postoperative complication, decreased morbidity, and cost savings while preserving patient satisfaction and quality of life (Greco et al., 2014). Due to the use of multimodal pain management strategies, ERP is consistently associated with improvements in pain scores. Patients in an ERP also have a more rapid return to baseline functional status (Groot et al., 2014).

The enhanced recovery after surgery (ERAS) model at the University of Virginia was piloted on their colorectal surgery service with outstanding results. As part of a quality initiative project, the ERAS program was then modified for the gynecologic surgical population. This encompassed all women undergoing major gynecologic surgeries (Thiele et al, 2015).

Enhanced Recovery Pathways ERP protocols address preoperative patient counseling, preoperative fasting, preoperative bowel preparation, early initiation of oral intake, early postoperative mobilization, appropriate use of drains and catheters, facilitation of perioperative euvolemia and normothermia, and multimodal analgesia. ERP has been rigorously studied in many surgical specialties. Data showing benefit of ERP principles and protocols is most robust in colorectal surgery, but it has also been implemented with similar positive outcomes in a variety of other surgical specialties including vascular surgery, thoracic surgery, cardiac surgery, urology, 
hepatobiliary surgery, orthopedics, as well as in benign gynecology and gynecologic oncology (Bell et al., 2013).

A growing body of evidence outside of gynecology including randomized controlled trials (Adamina et al., 2011) has shown that enhanced recovery speeds convalescence and reduces morbidity and cost while maintaining patient satisfaction and quality of life (Khan et al, 2010). Few groups have tested enhanced recovery in gynecologic surgery, and most cohorts were small and included only patients with benign disorders (Eberhart et al, 2008). Data regarding Clinical pathway (CP) in gynecology and gynecologic oncology is relatively spare when compared with other surgical fields and there are no published randomized trials ( $\mathrm{Lu}$ et al, 2012).

Nursing staff act as key coordinators in the improvement of efficiency and optimization of hospital resources. The participation of the maternity nurse is critical to successful ERP development and implementation (Smeltzer et al, 2010).

\section{SIGNIFICANCE OF STUDY:}

Enhanced recovery pathways that could be carried out by a maternity nurse in gynecologic surgery may result in significant improvement of postoperative outcomes. These include earlier return of gastrointestinal function, excellent pain management with significantly reduced opioids requirements, decreased length of hospital stay, excellent patient satisfaction combined with substantial reductions while maintaining stable complication and readmission rates (Kalogera et al., 2013). Few groups have tested enhanced recovery pathways in gynecologic surgery, and most cohorts were small and included few patients with benign disorders (Sjetne et al, 2009). Meanwhile no studies have been conducted about this issue in Port Said. Therefore, this study aims to determine the effect of clinical pathways postoperative nursing care for women undergoing gynecologic operations at Port Said city hospitals.

\section{AIM OF STUDY:}

The aim of the present study is to; investigate the effect of clinical pathways of postoperative nursing care for patients undergoing gynecologic operations on the postoperative outcome. 


\section{SUBJECT AND METHODS:}

\section{A. Technical design:}

This design covers the research design, settings, subjects and tools of data collection.

\section{Research design:}

A quasi-experimental design was utilized in this study

\section{Setting:}

To ensure generalization of the study results on Port Said city, this study was carried out in the inpatient (obstetric and gynecological department) at three governmental hospitals located in Port Said city as: 1- Port Said General Hospital 2- Port Fouad Hospital and 3- El-Tadamon Hospital.

\section{Sample:}

A purposive sample of patients who attended the study setting and fulfilling the following inclusion and exclusion criteria were recruited for this study.

\section{Inclusion criteria:}

-Woman age 20-45 years of age

- Patient undergoing major gynecological operations.

- The patient was free from chronic disease.

- The patient had no comorbidities associated with the operation.

\section{Exclusion criteria:}

- Patients undergoing oncologic operations.

- Minimally invasive gynecological procedures.

\section{The sample was divided into two groups:}

- Control group: composed of 56 women managed by routine pre and postoperative care of the hospital

- Study group: composed of 56 the clinical pathway management was used for women to hasten recovery and attenuate the stress response associated with surgery. Key elements common to all enhanced recovery pathways (a term coined by Dr. Kehlet) include: 
preoperative patient education, reduction of preoperative fasting, omission of bowel preparation, preoperative normovolemia, limited use of nasogastric tubes and drains, early removal of urinary catheters, aggressive multimodal analgesia to minimize opiate consumption, early postoperative mobilization, and early enteral nutrition.

\section{TOOLS FOR DATA COLLECTION:}

A structured interviewing schedule was designed, tested for validity and reliability and utilized by researcher to collect the necessary data. It entailed two parts:

Part I. This includes;

- Personal and socio-demographic characteristics about the study subjects such as (age, level of education and occupation,......etc).

- Obstetric history such as gravida, Para, abortions,... etc.).

- Present Gynecological history include (chief complain, medical diagnosis, time course of the current problem,....etc.).

\section{Part II. Assessment sheet including four sub-sections:}

(1) This include the physical examination (general appearance, vital signs, abdominal examination, etc.). Investigations which include (ancillary and specific investigations). Preoperative components which include (pre-operative preparation, informed consent, preoperative counseling and care of the patient).

(2) Patient record diary and pathway checklist was instituted and used for all inpatients postoperatively which includes (vital signs monitoring, early post-operative diet, respiratory care, mobilization, bladder and bowel care, Pain scoring chart....etc.

(3) The main outcome on which the comparison was made between the study and control group include postoperative hypotension, mobilization, time catheter removal, return of gastrointestinal function, pain control, length of hospital stay, morbidity, and cost.

(4) Patient satisfaction record mentioned by RAJESWAR, (2011) was used for the study group at the end of the program which evaluates 7 items: ( Information nurse was given- Ease of getting information-Information given by nurse -Skill and competence of nurse -Concern and caring by nurse -Privacy -Discharge instructions). 


\section{Scoring system:}

Concerning the performance practiced by nurses or the researcher for the control and study group, a correct response was scored 1 and the incorrect zero for each part, the scores of the items were summed-up and the total divided by the number of the items, giving a mean score for the part. Theses scores were converted into a percent score, and means and standard deviations were computed. The skill performance was considered satisfactory if the percent score was $60 \%$ or more and unsatisfactory if less than $60 \%$.

\section{B- Administrative design:}

An official letter from the dean of the faculty of nursing was sent to the director of the selected area of study. The director of each selected setting was contacted and informed in order to obtain permission to include the patients and nurses for the present research. Participants were reassured about the confidentiality of any obtained information.

\section{C- Operational design:}

The study field of work was carried out through the following phases:

\section{Preparation phase:}

During this phase, the researcher reviewed local and international literature to get more knowledge about the study subject. This also helped in designing the study tools. The tools were then prepared and validated through experts' opinions. The interview schedule and physical examination sheets were developed by the researcher after extensive review of the related literature. Tools were tested for content validity by five experts in the field of obstetrics and gynecological nursing. The recommended modifications were done and final form was made ready for use. Then, an evidence based guideline regarding clinical pathway of pre and postoperative nursing care for patients undergoing gynecological operations was prepared.

\section{Pilot study}

This was carried out over a period of one month. It was conducted on $10 \%$ of total sample size to evaluate the clarity and feasibility of the study tools. Necessary modifications were carried out as revealed from the pilot study. The study tool was revised, redesigned and rewritten according to obtained results and acceptance of final form. 


\section{Field work:}

Data collected through a period of six months, from first of December 2016 to the end of May 2017. Data related to the control group were first obtained, and then followed by collecting data of the study group. The researcher obtained an informed consent from every patient about her participation. The aim of the study was explained to every woman before participation, which was totally voluntary and an oral consent was obtained. Women were assured that the study maneuver will cause no actual or potential harm on them and professional help will be provided whenever needed. The researcher started to collect data through three phases: 1) interviewing, 2) assessment and 3) evaluation.

\section{1) Interviewing phase}

All patients in both groups were interviewed (structured interview) to collect data related to sociodemographic characteristics, obstetric profile, and current surgical history. Personal interview was done for both groups and it takes 10 minutes for each one.in addition, it was done before surgery 5-1 days.

\section{2) Assessment Phase.}

Concerning the control group the role of the researcher was just observing and recording the tasks performed by nurses concerning pre and postoperative care of patients. However, for patients in the study group she implemented the nursing care plan which includes all the components of the key elements of the clinical pathway management during the period of hospitalization postoperatively until discharge from hospital.

\section{3) Evaluation phase.}

This phase started immediately after the operation where all parameters of the clinical pathway management and its effect on the postoperative outcome that are previously mentioned were noted for the comparison between the study and control group. Lasted for one month postoperatively, whereas the researcher followed the patient at home by calling them once a week to assess their health and any related complications.

\section{Statistical design}

All statistical analyses were performed using SPSS for windows version 20.0 (SPSS, Chicago, IL). Data were tested for normality of distribution prior to any calculations. Continuous data were 
expressed in mean \pm standard deviation (SD) as all continuous data were normally distributed. Categorical data were expressed in number and percentage. The comparisons were determined using Student's t test for variables with continuous data and using chi-square test was used for comparison of variables with categorical data. Statistical significance was set at $\mathrm{p}<0.05$.

\section{RESULTS:}

Table (1): presents distribution of the women in the clinical pathway and control groups according to their socio-demographic characteristics. As regards age, it was observed that almost half of women in the study and control groups were $>45$ years (42.9\% vs. $58.9 \%$ respectively). The percentage of women who had secondary level of education was higher in the control group (28.6\% vs. $23.2 \%$ respectively) compared to the control group, but with no statistical significant difference. Meanwhile they were more likely to be housewives and more than half of them $(57.1 \%$ vs. $69.6 \%$ respectively) were married with no statistical significant difference.

Table (2): demonstrates the type of surgery among women in the two groups. It is obvious that total abdominal hysterectomy was the most common surgery with the highest percentage in both groups (51.8\% vs. $60.7 \%$ respectively). This is followed by subtotal hysterectomy, myomectomy, salpingo-oophrectomy then cystectomy. Differences observed are not statistically significant. The total is not exclusive.

Table (3): shows that women in the study group had less mean duration of fasting hours (NPO) compared to those in the control group with statistically significant difference $(8.7 \pm 1.3$ vs. 26.5 \pm 16.3 respectively). Moreover, none of them received enema compared to the control group who received it more than one time $(0.0 \%$ vs. $57.1 \%$ respectively). In addition women in both groups received antibiotics and IV fluids during the preoperative period.

Table (4): shows Patients underwent gynecological operation in the study group were significantly more likely to have no vomiting compared to those in the control group $(\mathrm{P}=<0.001)$. Thus lesser number $10(17.9 \%)$ were in need to antiemetic compared to $44.6 \%$ in the control group. As for the level of pain encountered by patients during the postoperative period, the same table revealed that women in the study group experience less mean score compared to those in the control group ( $8.4 \pm 0.9$ vs. $8.7 \pm 0.8$ respectively), thus they showed lesser need for analgesia (1.9 \pm 1.1 vs. $2.4 \pm 0.9$ respectively) with statistical significant difference. 
Table (5): demonstrates that almost two thirds of women in the study group (60.7\%) had begun their first time of sitting <3 hours compared to only one fourth (25.5\%) of the control group, with statistical significant difference $(\mathrm{P}=<0.001)$. Meanwhile, all of them started ambulation out of bed within the first 6 hours of the operation compared to only $60.7 \%$ of the control group. Also the difference observed is statistically significant $(\mathrm{P}=<0.001)$.

Table (6): shows that women in the study group were significantly ( $\mathrm{P}=<0.001)$ more likely to start oral fluids within the first 10 hours after the operation compared to those in the control group (5.4 \pm 1.0 vs. $15.8 \pm 8.3$ respectively). Meanwhile, they received a higher mean amount of oral fluids (188.6 \pm 55.2 vs. $129.6 \pm 60.9$ respectively) and the majority of them (96.4\%) begun regular diet within the first 24 hours after the operation compared to those in the control group (19.6\%). Difference observed is statistical significant.

Table (7): points to a statistically significant difference between the study and control groups concerning the time of removing bladder catheter and drains $(\mathrm{p}<0.001)$. The mean time of removal of both drains was lesser in the study group than those in the control group (15.3 $\pm 5.7 \&$ $45.1 \pm 5.6$ vs. $20.5 \pm 10.9 \& 66.2 \pm 27.9$ respectively). Moreover, patients in the study group were more likely to have lesser mean time of first bowel sounds, first passage of flatus, and first defecation after surgery $(3.7 \pm 0.9,6.3 \pm 1.0$ and $10.5 \pm 1.9$ vs. $6.9 \pm 1.1,13.2 \pm 1.4$ and $27 \pm 2.4$ hours respectively). Differences observed are statistically significant $(\mathrm{p}=<0.001 *)$.

Table (8) \& figure (1): shows that the mean duration of hospitalization in the study group was significantly shorter than those in the control group ( $1.8 \pm 0.4$ vs. $2.4 \pm 0.5$ respectively). Differences observed is highly significant ( $T$ test $6.718^{*} \& \mathrm{p}<0.001$ ). The same table reveals that women in the study group were less likely to suffer from complications as; abdominal cramps, distension and constipation compared to those in the control group.

Table (9) \& figure (2): Describes the women satisfaction related to the care provided to the study group (clinical pathway nursing management). Rating was mostly very good and excellent (35.7\% and 57.2 respectively) and less than one tenth who gave the score of good (7.1\%) to the 7 parameters showing patient's satisfaction. 
Table (1): Distribution of the studied women according to their Socio-demographic Characteristics $(n=112)$.

\begin{tabular}{|c|c|c|c|c|c|c|}
\hline \multirow[t]{2}{*}{ Variables } & \multicolumn{2}{|c|}{$\begin{array}{l}\text { Study Group } \\
(\mathrm{n}=56)\end{array}$} & \multicolumn{2}{|c|}{$\begin{array}{l}\text { Control Group } \\
(n=56)\end{array}$} & \multicolumn{2}{|c|}{ Chi square test } \\
\hline & No. & $\%$ & No. & $\%$ & $\mathrm{X}^{2}$ & $\mathrm{p}$ \\
\hline \multicolumn{7}{|l|}{ Age (years) } \\
\hline$<35$ & 11 & 19.6 & 5 & 8.9 & \multirow{3}{*}{3.902} & \multirow{3}{*}{0.142} \\
\hline $35-45$ & 21 & 37.5 & 18 & 32.1 & & \\
\hline$>45$ & 24 & 42.9 & 33 & 58.9 & & \\
\hline Mean \pm SD & \multicolumn{2}{|c|}{$43.1 \pm 7.7$} & \multicolumn{2}{|c|}{$45.1 \pm 5.9$} & $1.588^{*}$ & 0.115 \\
\hline \multicolumn{7}{|l|}{ Educational } \\
\hline \multicolumn{7}{|l|}{ level } \\
\hline Illiterate & 2 & 3.6 & 5 & 8.9 & \multirow{5}{*}{4.660} & \multirow{5}{*}{0.324} \\
\hline Read/write & 16 & 28.6 & 8 & 14.3 & & \\
\hline Basic & 14 & 25.0 & 13 & 23.2 & & \\
\hline Secondary & 13 & 23.2 & 16 & 28.6 & & \\
\hline High & 11 & 19.6 & 14 & 25.0 & & \\
\hline \multicolumn{7}{|c|}{ Marital status } \\
\hline Married & 32 & 57.1 & 39 & 69.6 & \multirow{4}{*}{5.308} & \multirow{4}{*}{0.151} \\
\hline Widow & 9 & 16.1 & 11 & 19.6 & & \\
\hline Single & 8 & 14.3 & 2 & 3.6 & & \\
\hline Divorced & 7 & 12.5 & 4 & 7.1 & & \\
\hline \multicolumn{7}{|l|}{ Job } \\
\hline Housewife & 31 & 55.4 & 37 & 66.1 & & \\
\hline Working & 25 & 44.6 & 19 & 33.9 & 1.348 & 0.246 \\
\hline
\end{tabular}


Table (2): Distribution of the Studied Women According to the Type of Gynecological operation $(\mathrm{n}=112)$

\begin{tabular}{|l|l|l|l|l|l|l|}
\hline Variables & $\mathrm{N}$ & $\%$ & $\mathrm{~N}$ & $\%$ & $\mathrm{X}^{2}$ & $\mathrm{P}$ \\
\hline Total abdominal hysterectomy & 29 & 51.8 & 34 & 60.7 & 0.907 & 0.341 \\
Myomectomy & 9 & 16.1 & 8 & 14.3 & 0.069 & 0.792 \\
Subtotal hysterectomy & 14 & 25.0 & 12 & 21.4 & 0.200 & 0.654 \\
Salpingo-oophrectomy & 9 & 16.1 & 8 & 14.3 & 0.069 & 0.792 \\
Cystectomy & 3 & 5.4 & 2 & 3.6 & 0.209 & 0.647 \\
\hline
\end{tabular}

Table (3): Distribution of the Studied Women According to the fasting hours and pre-operative medications $(\mathrm{n}=112)$

\begin{tabular}{|c|c|c|c|c|c|c|}
\hline \multirow[t]{2}{*}{ Variables } & \multicolumn{2}{|c|}{$\begin{array}{l}\text { Study Group } \\
(\mathrm{n}=56)\end{array}$} & \multicolumn{2}{|c|}{$\begin{array}{l}\text { Control Group } \\
(\mathbf{n}=56)\end{array}$} & \multirow{2}{*}{\begin{tabular}{|l}
$\begin{array}{l}\text { Chi } \\
\text { square } \\
\text { test }\end{array}$ \\
$\mathbf{X}^{2}$ \\
\end{tabular}} & \multirow[b]{2}{*}{$\mathbf{P}$} \\
\hline & No & $\%$ & No. & $\%$ & & \\
\hline Fasting hours (NPO) & \multicolumn{2}{|c|}{$8.7 \pm 1.3$} & \multicolumn{2}{|c|}{$26.5 \pm 16.3$} & $8.133^{*}$ & $<0.00$ \\
\hline \multicolumn{7}{|l|}{ Enema times } \\
\hline None & 56 & 100.0 & 24 & 42.9 & & \\
\hline 1 & 0 & 0.0 & 21 & 37.5 & & \\
\hline 2 & 0 & 0.0 & 11 & 19.6 & 44.800 & $<0.001$ \\
\hline Antibiotics received & 56 & 100.0 & 56 & 100.0 & 0 & 1.000 \\
\hline IV fluids (ringer lactate) & 56 & 100.0 & 56 & 100.0 & 0 & 1.000 \\
\hline
\end{tabular}


Table (4): Distribution of the Studied Women According to the frequency of vomiting, level of pain and the need for analgesia at POD $(n=112)$

\begin{tabular}{|c|c|c|c|c|c|c|}
\hline \multirow[b]{2}{*}{ Variables } & \multicolumn{2}{|c|}{$\begin{array}{l}\text { Study Group } \\
(\mathbf{n}=\mathbf{5 6})\end{array}$} & \multicolumn{2}{|c|}{$\begin{array}{l}\text { Control Group } \\
(n=56)\end{array}$} & \multicolumn{2}{|c|}{ Chi square test } \\
\hline & No. & $\%$ & No. & $\%$ & $\mathbf{X}^{2}$ & $\mathbf{P}$ \\
\hline \multicolumn{7}{|c|}{ Frequency of Vomiting } \\
\hline None & 23 & 41.1 & 3 & 5.4 & & \\
\hline $1-2$ & 30 & 53.6 & 18 & 32.1 & & \\
\hline 3 or more & 3 & 5.4 & 35 & 62.5 & 45.332 & $<0.001$ \\
\hline Need anti-emetics & 10 & 17.9 & 25 & 44.6 & 9.351 & 0.002 \\
\hline \multicolumn{7}{|l|}{ Level of Pain } \\
\hline Mild & 10 & 17.9 & 1 & 1.8 & & \\
\hline Moderate & 18 & 32.1 & 20 & 35.7 & & \\
\hline Severe & 28 & 40.0 & 35 & 62.5 & & \\
\hline & & & & & 8.660 & 0.034 \\
\hline Mean \pm SD & \multicolumn{2}{|c|}{$8.4 \pm 0.9$} & \multicolumn{2}{|c|}{$8.7 \pm 0.8$} & $2.257 *$ & 0.026 \\
\hline \multicolumn{7}{|c|}{ The need for analgesia } \\
\hline None & 4 & 7.1 & 1 & 1.8 & & \\
\hline $1-2$ & 40 & 71.4 & 32 & 57.1 & & \\
\hline $3-4$ & 12 & 21.4 & 23 & 41.1 & 6.146 & 0.046 \\
\hline Mean \pm SD & \multicolumn{2}{|c|}{$1.9 \pm 1.1$} & \multicolumn{2}{|c|}{$2.4 \pm 0.9$} & $1.375^{*}$ & 0.019 \\
\hline
\end{tabular}


Table 5: Distribution of the Studied Women According to their ambulation during

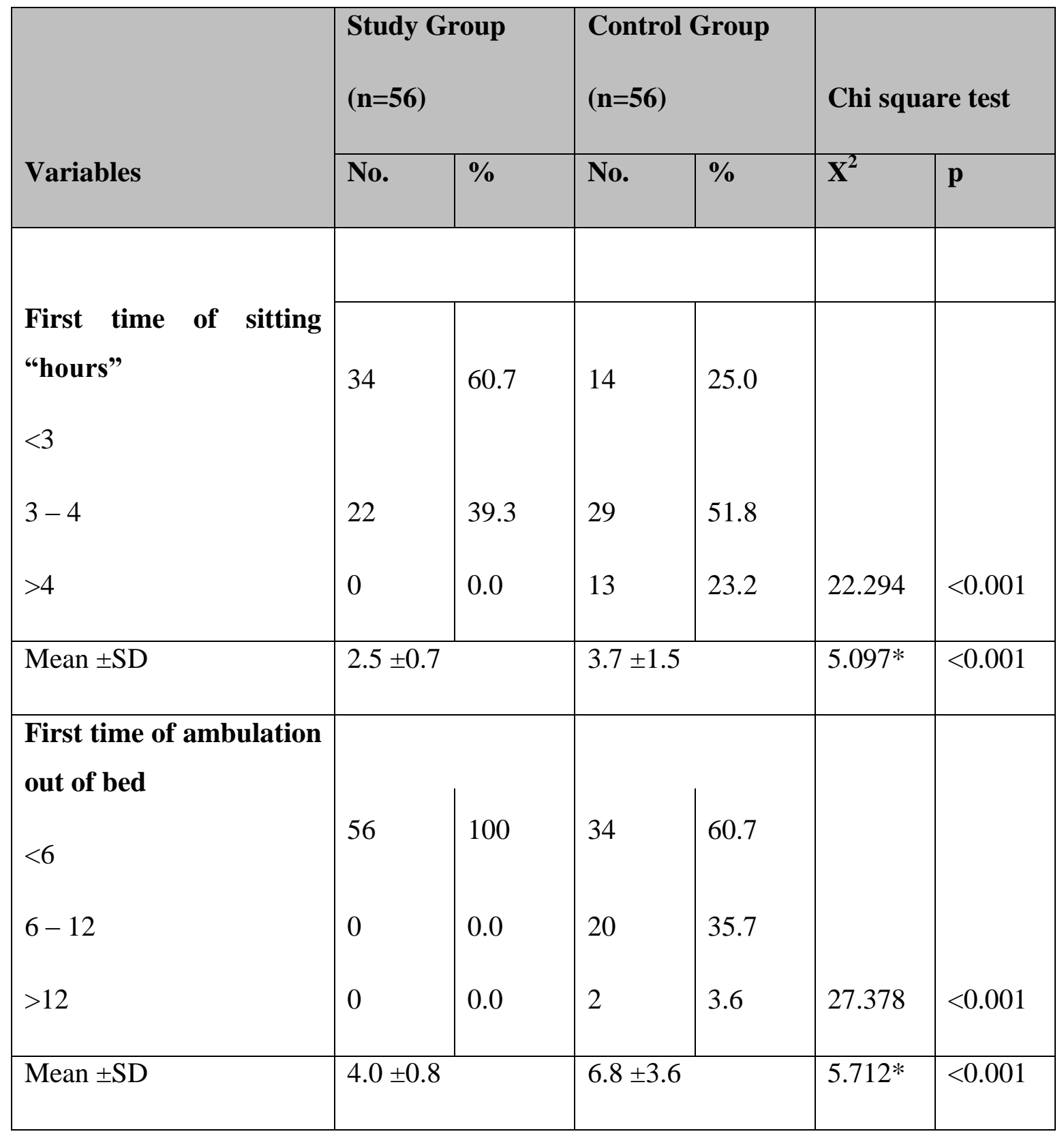

postoperative period $(n=112)$ 
Table (6) : Distribution of the Studied Women According to their Postoperative Nourishment $(n=112)$

\begin{tabular}{|c|c|c|c|c|c|c|}
\hline \multirow[b]{2}{*}{ Variables } & \multicolumn{2}{|c|}{$\begin{array}{l}\text { Study Group } \\
(\mathrm{n}=56)\end{array}$} & \multicolumn{2}{|c|}{$\begin{array}{l}\text { Control Group } \\
(n=56)\end{array}$} & \multicolumn{2}{|c|}{ Chi square test } \\
\hline & No. & $\%$ & No. & $\%$ & $\mathbf{X}^{2}$ & $\mathbf{P}$ \\
\hline \multicolumn{7}{|l|}{ Initiation of oral fluids (hours) } \\
\hline 10 or less & 33 & 58.9 & 4 & 7.1 & & \\
\hline $11-20$ & 23 & 41.1 & 26 & 46.4 & & \\
\hline$>20$ & 0 & 0.0 & 26 & 46.4 & 48.913 & $<0.001$ \\
\hline Mean \pm SD & \multicolumn{2}{|c|}{$5.4 \pm 1.0$} & \multicolumn{2}{|c|}{$15.8 \pm 8.3$} & $9.279^{*}$ & $<0.001$ \\
\hline \multicolumn{7}{|l|}{$\begin{array}{l}\text { Intake amount of oral fluids } \\
\text { (liter) }\end{array}$} \\
\hline$<100$ & 1 & 1.8 & 12 & 21.4 & & \\
\hline $100-200$ & 40 & 71.4 & 41 & 73.2 & & \\
\hline$>200$ & 15 & 26.8 & 3 & 5.4 & 17.320 & $<0.001$ \\
\hline Mean \pm SD & \multicolumn{2}{|c|}{$188.6 \pm 55.2$} & \multicolumn{2}{|c|}{$129.6 \pm 60.9$} & $6.401^{*}$ & $<0.001$ \\
\hline \multicolumn{7}{|l|}{$\begin{array}{l}\begin{array}{l}\text { Initiation of } \\
\text { (hours) }\end{array} \\
\text { regular diet } \\
\end{array}$} \\
\hline$<12$ & 19 & 33.9 & 0 & 0.0 & & \\
\hline $12-24$ & 35 & 62.5 & 11 & 19.6 & & \\
\hline$>24$ & 2 & 3.6 & 45 & 80.4 & 70.862 & $<0.001$ \\
\hline Mean \pm SD & \multicolumn{2}{|c|}{$14.6 \pm 5.2$} & \multicolumn{2}{|c|}{$37.3 \pm 17.9$} & $9.154 *$ & $<0.001$ \\
\hline
\end{tabular}


Table (7): Distribution of the Studied Women According to their Removal of Drain and Catheter as well as bowel mobility during the postoperative period $(n=112)$

\begin{tabular}{|c|c|c|c|c|c|c|}
\hline \multirow[b]{2}{*}{ Variables } & \multicolumn{2}{|c|}{$\begin{array}{l}\text { Study Group } \\
(\mathrm{n}=56)\end{array}$} & \multicolumn{2}{|c|}{$\begin{array}{l}\text { Control Group } \\
(n=56)\end{array}$} & \multicolumn{2}{|c|}{ Chi square test } \\
\hline & No. & $\%$ & No. & & $\overline{X^{2}}$ & $\mathbf{P}$ \\
\hline \multicolumn{7}{|l|}{ Time of removal of } \\
\hline bladder catheter (hours) & & & & & & \\
\hline$<12$ & 24 & 42.9 & 16 & 28.6 & & \\
\hline $12-24$ & 31 & 55.4 & 24 & 42.9 & & \\
\hline$>24$ & 1 & 1.8 & 16 & 28.6 & 15.726 & $<0.001$ \\
\hline Mean \pm SD & \multicolumn{2}{|c|}{$15.3 \pm 5.7$} & \multicolumn{2}{|c|}{$20.5 \pm 10.9$} & $3.401^{*}$ & $<0.001$ \\
\hline \multicolumn{7}{|l|}{ Time of removal of drains (hours) } \\
\hline 1 day & 4 & 7.1 & 0 & 0.0 & & \\
\hline 2 days & 29 & 51.8 & 19 & 33.9 & & \\
\hline 3 days or more & 23 & 41.1 & 37 & 66.1 & 9.350 & 0.009 \\
\hline Mean \pm SD & \multicolumn{2}{|c|}{$45.1 \pm 5.6$} & \multicolumn{2}{|c|}{$66.2 \pm 27.9$} & $4.938^{*}$ & 0.026 \\
\hline Bowel mobility (hours) & \multicolumn{2}{|c|}{ Mean \pm SD } & \multicolumn{2}{|c|}{ Mean \pm SD } & $\mathbf{T}$ & $\mathbf{P}$ \\
\hline First bowel sound & \multicolumn{2}{|c|}{$3.7 \pm 0.9$} & \multicolumn{2}{|c|}{$6.9 \pm 1.1$} & & \\
\hline First passage of flatus & \multicolumn{2}{|c|}{$6.3 \pm 1.0$} & \multicolumn{2}{|c|}{$13.2 \pm 1.4$} & & \\
\hline First passage of stool & \multicolumn{2}{|c|}{$10.5 \pm 1.9$} & \multicolumn{2}{|c|}{$27 \pm 2.4$} & 79.143 & $<0.001$ \\
\hline
\end{tabular}


Table (8): Distribution of the Studied Women According to their Hospital stay and complications encountered during the Postoperative Period $(n=112)$

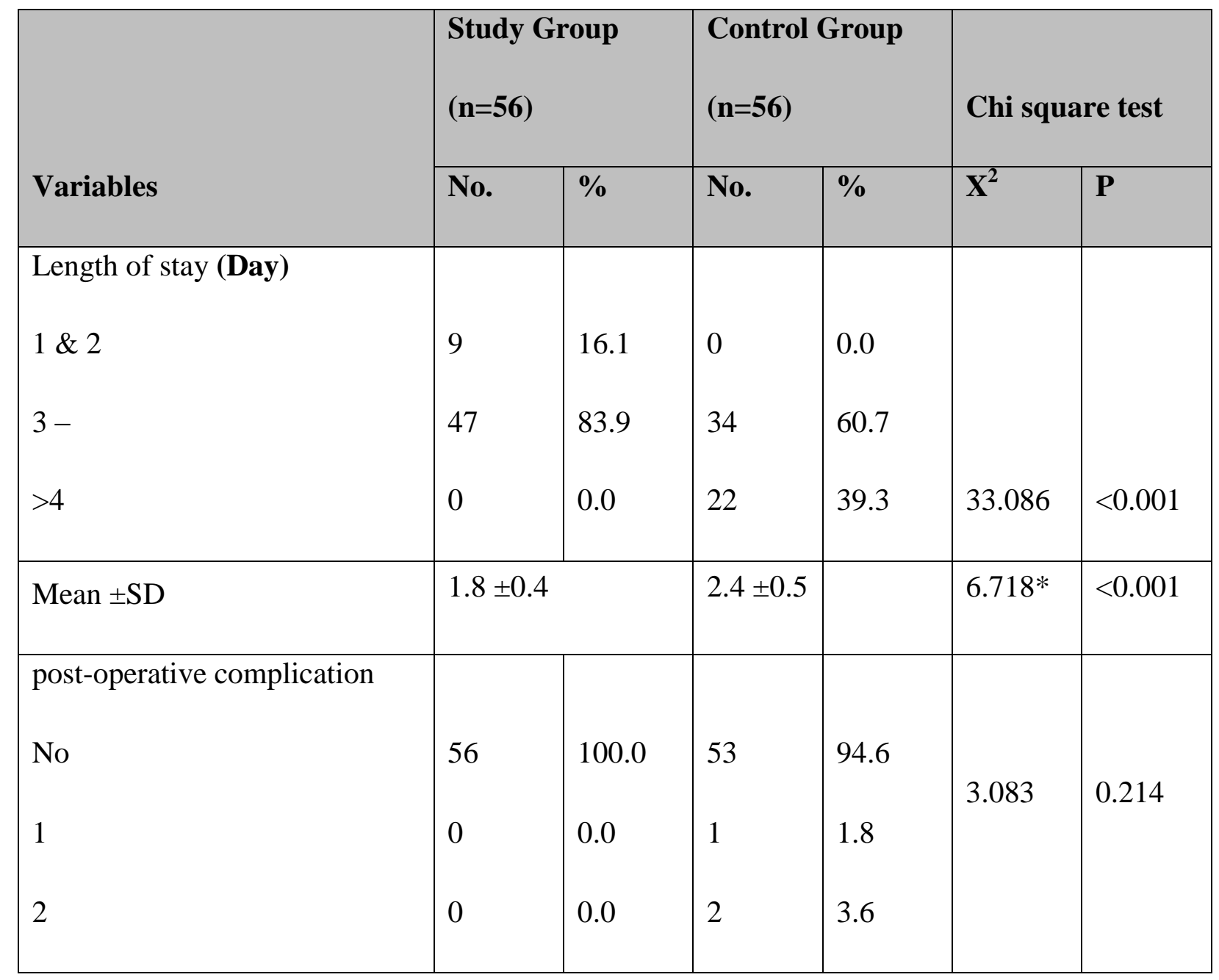




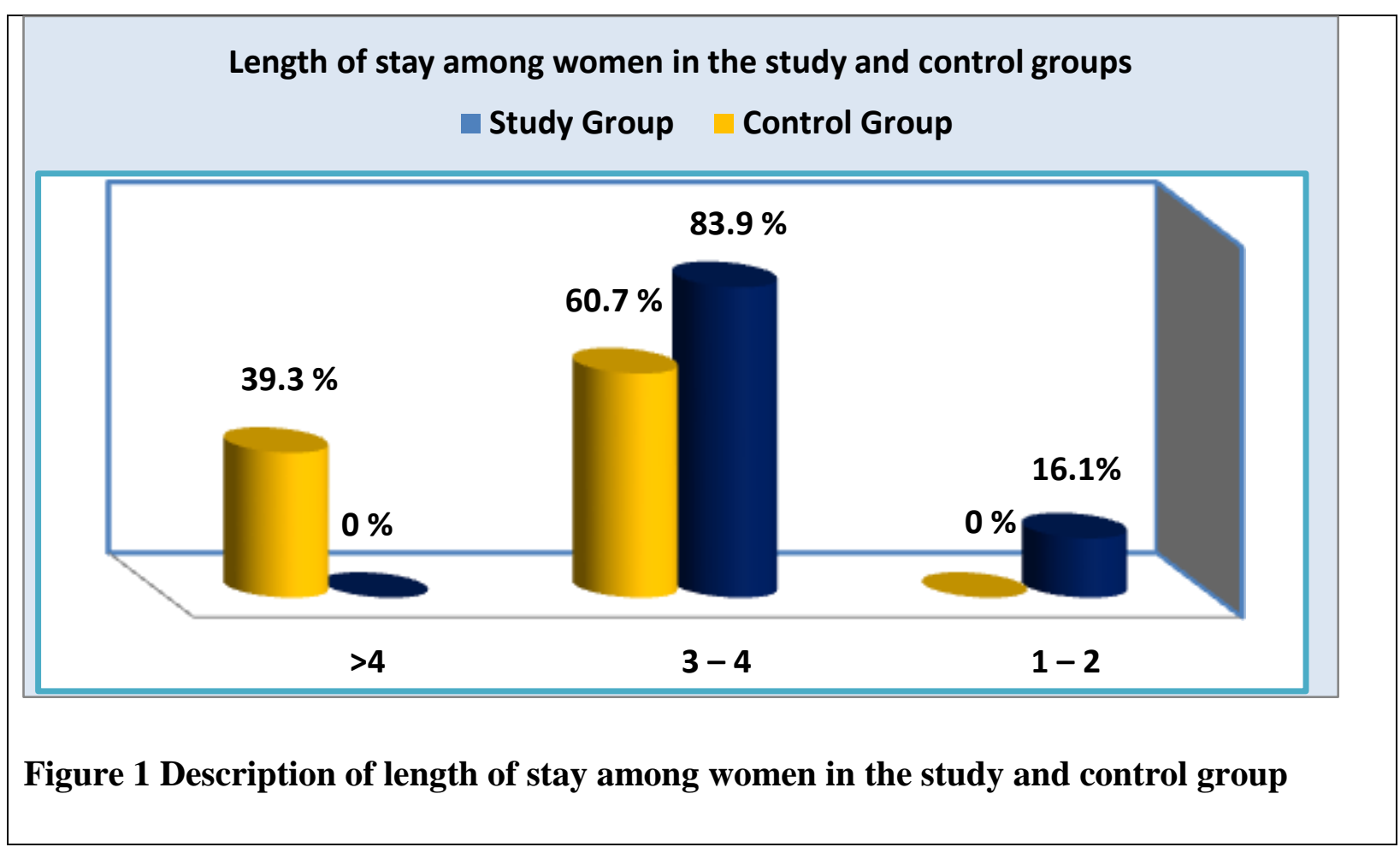


Table (9): Distribution of the Clinical pathway group According to their satisfaction

\begin{tabular}{|c|c|c|c|c|c|c|}
\hline \multirow{2}{*}{ Variables } & \multicolumn{2}{|c|}{ Excellent } & \multicolumn{2}{|c|}{ Very good } & \multicolumn{2}{|c|}{ Good } \\
\hline & No. & $\%$ & No. & $\%$ & No. & $\%$ \\
\hline $\begin{array}{l}\text { 1) Information nurse was given: How clear and } \\
\text { complete the nurse's expectations were about tests, } \\
\text { treatments, and what to expect. }\end{array}$ & 29 & 51.8 & 24 & 42.9 & 3 & 5.4 \\
\hline $\begin{array}{l}\text { 2) Ease of getting information: willingness of nurse to } \\
\text { answer patient's questions. }\end{array}$ & 34 & 60.7 & 18 & 32.1 & 4 & 7.1 \\
\hline $\begin{array}{l}\text { 3) Information given by nurses: how well nurses } \\
\text { communicated with patients, families, and doctors. }\end{array}$ & 28 & $\mathbf{5 0}$ & 23 & 41.1 & 5 & 8.9 \\
\hline $\begin{array}{l}\text { 4) Skill and competence of nurses: how well things were } \\
\text { done, like giving medicine and handling IVs. }\end{array}$ & 35 & 62.5 & 18 & 32.1 & 3 & 5.4 \\
\hline $\begin{array}{l}\text { 5) Concern and caring by nurses: courtesy and respect } \\
\text { you were given; friendliness and kindness. }\end{array}$ & 29 & 51.8 & 25 & 44.6 & 2 & 3.6 \\
\hline 6) Privacy: provisions for your privacy by nurse. & 33 & 58.9 & 18 & 32.1 & 5 & \begin{tabular}{|l|}
8.9 \\
\end{tabular} \\
\hline $\begin{array}{l}\text { 7) Discharge instructions: how clearly and completely } \\
\text { the nurse told you what to do and what to expect when } \\
\text { you left the hospital. }\end{array}$ & 40 & 71.4 & 11 & 19.6 & 5 & 8.9 \\
\hline Total score & \multicolumn{2}{|c|}{$7.1 \%$} & \multicolumn{2}{|c|}{$35.7 \%$} & \multicolumn{2}{|c|}{$57.2 \%$} \\
\hline Range & \multicolumn{6}{|c|}{$21-35$} \\
\hline Mean \pm SD & \multicolumn{6}{|c|}{$31.6 \pm 3.2$} \\
\hline
\end{tabular}




\section{$7.1 \%(n=4)$}

$57.2 \%(n=32)$

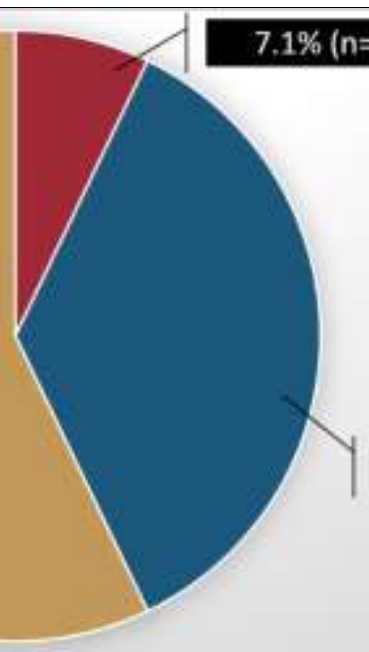

- Good

- Very good

$=$ Excellent

$35.7 \%(n=20)$

Figure 2. Distribution of the patients total satisfaction

DISCUSSION:

Enhanced Recovery After Surgery (ERAS) is a standardized, highly coordinated interdisciplinary perioperative surgical care program that incorporate evidence-based interventions to minimize surgical stress, improve physiological and functional recovery, reduce complications, and facilitate earlier discharge from the hospital and reduced cost of care (Kehelt \& Wilmore, 2002). For implementation to be successful, nurses were found to be a key in providing education, perioperative care, and postoperative evaluation, as well as cost containment (Verheijen et al., 2012).

The key principles of the ERAS protocol or clinical pathway management include; pre-operative counseling, preoperative nutrition, avoidance of perioperative fasting and carbohydrate loading up to 2 hours preoperatively, standardized anesthetic and analgesic regimens (epidural and non-opiod analgesia) and early mobilization (Pruthi et al., 2003 \& Pruthi ., 2010).

Studies have documented an association between the use of clinical guidelines and pathways and positive outcomes including the provision of high-quality, cost-effective care, greater patient and staff satisfaction, and better resource management in a variety of clinical contexts (Rotter et al., 2010 \& Vandvik et al., 2013) . Other studies have documented that the adoption of clinical pathways can reduce length of stay and decrease medical cost (Micieli et al., 2000 \& Wang, 2013). 
In order to investigate the extent to which the local hospital are adhering to national guidelines. The present study was undertaken to investigate the effect of clinical pathway of postoperative nursing care for patients undergoing gynecologic operations at Port Said hospitals. The study could provide important baseline information on the delivery of health care in Port Said hospital and the potential for improvements in health care quality. Similarly, Kinsman (2004) and Rello et al., (2002) studies have been conducted with the objectives of the using clinical pathways to improve quality of care, to reduce costs, and to decrease inappropriate variation in health care use (Kinsman, 2004 \& Rello et al., 2002).

The current study shows that women in the study group had less mean duration of fasting hours compared to those in the control group with statistically significant difference. Wisely et al., (2016) supported this evidenced key element and reported that almost two thirds $(61 \%)$ of the enhanced recovery group had a shorter fasting time $(<24 \mathrm{~h})(\mathrm{p}<0.001)$ compared to $39 \%$ in the control group. This could be explained by the fact that the practice of fasting patients from midnight is used to avoid pulmonary aspiration after elective surgery; however, there is no evidence to support this. Crowe et al., (1984) mentioned that preoperative fasting actually increases the metabolic stress, hyperglycemia and insulin resistance, which the body is already prone to during the surgical process. Changing the metabolic state of patients by shortening preoperative fasting not only decreases insulin resistance, but reduces protein loss and improves muscle function (Thorell et al., 1999).

The current study findings showed that patients underwent gynecological operation in the study group were significantly more likely to have no vomiting compared to those in the control group $(\mathrm{P}=<0.001)$. Thus less than one fifth of them were in need to antiemetic compared to almost half in the control group. This is supported by Wijk et al., (2014) who found that $34 \%$ pre-ERAS vs. $39(46 \%)$ where in need for anti-emetics day $0(\mathrm{p}=0.084)$ and $9 \%$ vs. $16 \%$ who received more than one dose.

Evidence has shown that improper relief of postoperative pain has harmful physiological and psychological consequences for patients, increases morbidity, mortality and re-admission for pain management, extends hospitalization, and delays patients' return to their normal activities, with resulting increase in costs (Joshi et al., 2005). Concerning the level of pain experienced by patients during the postoperative period, the present result reveals that women in the study group experience less mean score compared to those in the control group, thus they showed lesser need 
for analgesia with statistical significant difference. This could be attributed to alleviation of stress and clearing up misconceptions associated with gynecological operation during the preoperative counseling (Apfelbaum et al., 2003).

Postoperative physical inactivity is a risk factor for various adverse outcomes. Gillinov et al., (1992) reported that postoperative prolonged bed rest is a risk factor for pulmonary embolism following cardiac surgery.

A systematic review showed that immobilization defined as confinement to bed and/or armchair was associated with 6 fold increase in deep vein thrombosis (Samama et al, 2003). A randomized trial including patients who underwent a coronary artery bypass surgery revealed that systematic turning activity in bed decreased the risk of postoperative fever and Length of Stay (LOS) in intensive care unit .Ambulation at least five times per day in the hallways is also prescribed (Chulay et al, 1982).

According to the present study finding, almost two thirds of women in the study group had begun their first time of sitting $<3$ hours compared to only one fourth of the control group, with statistical significant difference ( $\mathrm{P}=<0.001)$. Meanwhile, all of them started ambulation out of bed within the first 6 hours of the operation compared to more than two thirds of the control group. In agreement with the previous mentioned finding Vlug et al., (2012) shows that a failure to mobilize is a common reason for ER protocol deviation and is associated with increased length of stay suggesting that early mobilization is a key to achieve the beneficial outcomes associated with ERP.

Based on the present study finding, women in the study group were significantly $(\mathrm{P}=<0.001)$ more likely to start oral fluids within the first 10 hours after the operation compared to those in the control group. Meanwhile, they received a higher mean amount of oral fluids and the majority of them begun regular diet within the first 24 hours after the operation compared to those in the control group. Whereas Gerardi et al, (2008) demonstrated that time to tolerance of diet decreased by 3 days in the enhanced recovery group as compared to the control group. Meanwhile, Kalogera et al, 2013 showed that despite early feeding was associated with a higher rate of nausea and vomiting in the ER group, 87\% rated their satisfaction with nausea and vomiting control as excellent or very good, suggesting that early feeding is overall well tolerated. 
Significant differences in the postoperative bowel mobility were observed between present study and the control groups $(\mathrm{p}=<0.001 *)$. Patients in the study group were more likely to have lesser mean time of first bowel sounds, first passage of flatus, and first defecation after surgery. In the same line Al-Ghareeb et al., (2013) study in Kingdom Saudi Arabian about Effect of Early Oral Hydration on Post Cesarean Outcomes reported that the experimental group significantly had earlier initiation of bowel sounds with a median value of 3 hours vs. 6.5 hours in the control group. Consequently the bowel movement returned significantly earlier with median duration of 29 hours among the study group compared to 54 hours among the control group.

Concerning the time of removing bladder catheter and drains the present study reveals a statistically significant difference between the two groups $\quad(p<0.001)$. The mean time of removal of both drains was lesser in the study group than those in the control group. In the same line Barber et al., (2016) showed early removal (1 day) compared to standard removal (approximately 4 days). In this respect Joshi et al, (2016) study in India mentioned that the Foley catheters could be removed on postoperative day one for patients who have undergone laparoscopic procedures and by postoperative day two for patients who have undergone open abdominal procedures.

Concerning the length of stay (LOS), the present study finding has indicated that the mean duration of hospitalization in the study group was significantly shorter than those in the control group. This is supported by Dickson et al., (2012) who found that an ERAS pathway in women undergoing abdominal hysterectomy for benign disease had decreased median LOS from 3 days to 1 day following implementation ( $\mathrm{p}<0.001)$. Also, Modesitt et al., (2016) study who compared patients on an ERAS pathway with those traditional control using a conventional protocol found that the median LOS decreased from 3 to 2 days ( $\mathrm{p}=0.007$ ). Additionally in agreement with the above mentioned finding Kalogera et al., (2013) study included women with gynecologic malignancy in a retrospective study evaluating the implementation of an ERAS study in laparotomy for complex gynecologic surgery. They found that median LOS was 4 days less in the ERAS group than in the conventional group (8.7 vs. 11.9 days). Moreover, Eva et al., (2016) demonstrated that the mean length of stay LOS was $4.29 \pm 2.78$ days for patients who followed ERAS, significantly reduced compared to $7.23 \pm 5.68$ days for the control group $(\mathrm{p}<0.001)$.

Women's satisfaction related to the care provided was assessed in the present study group (clinical pathway nursing management). The score given was mostly very good and excellent. Similarly, Minig et al., (2009) reported that post-operative satisfaction was significantly higher in 
ERAS group (82.8 vs. $71.7, \mathrm{p}>0.001)$ than in the traditional group and suggested that ERAS should be used after a complex gynecologic laparotomy.

\section{CONCLUSION:}

\section{Based on study findings, it can be concluded that:}

With the perspective of the impact of clinical pathway of postoperative nursing care for women undergoing gynecologic surgery, the study revealed women in the study group were more likely to move early out of bed after the operation than the control group, women in the study group were more likely to have shorter period of hospital stay than the control group. Statistically significant improvement in the postoperative outcome as well as decreasing the incidence of complications in the post-operative period, statistically significant improvement in women satisfaction related to clinical pathway care. Therefore, it can conclude that clinical pathway was effective in improving postoperative outcomes related to early ambulation, early oral intake, short length of stay and patient satisfaction.

\section{RECOMMENDATIONS:}

\section{Based on the results of the present study, the following recommendations were suggested:}

- Preoperative counseling should be done by maternity nurses about their postoperative course based on a risk assessment performed preoperatively.

- The clinical pathway management which proved to be successful should be integrated in the postoperative management protocol at the study setting and in other governmental hospitals.

- Health care setting should emphasize the importance of coordination between health care members relating to the application of the evidenced key elements of clinical pathway management.

- Training programs are recommended for nurses in order to enhance their knowledge and skills regarding clinical pathway management in order to be able to educate and counsel women about such evidence based practice.

- Further research is recommended using different protocol of management with different evidence based practices, with a large sample size and in different setting. 


\section{REFERENCES:}

Adamina M, Kehelt H, Tomlinson GA, Senagore AJ, Delaney CP. (2011): Enhanced recovery pathways optimize health outcomes and resource utilization: a meta-analysis of randomized controlled trials in colorectal surgery; 149:830-40.

Al-Ghareeb S A, Ahmad R E, Ahmad H. (2013): Effect of Early Oral Hydration on Post Cesarean Outcomes. Journal of American Science; 9(8).

Apfelbaum JL, Chen C, Mehta SS and Gan TJ. (2003): Postoperative pain experience: results from a national survey suggest postoperative pain continues to be undermanaged. Anesth Analg; 97:534-40.

Barber E, Van L. (2016): enhanced recovery pathways in gynecology and gynecologic oncology. PMC; 70(12): 780-792.

Bell A, Relph S, Sivashanmugarajan V, Yoong W. (2013): Enhanced recovery programs: do these have a role in gynecology? Journal of obstetrics and gynecology: the journal of the institute of obstetrics and gynecology; 33(6): 539-541.

Chulay M, Brown J, Summer W. (1982) Effect of postoperative immobilization after coronary artery bypass surgery. Crit Care Med ; 10:176-179.

Crowe PJ, Dennison A, Royle GT. (1984) The effect of pre-operative glucose loading on postoperative nitrogen metabolism. Br J Surg; 71:635-7.

De Groot JJ, Van ES LE, Maessen JM, Dejong CH, Kruitwagen RF, Slangen BF. (2014): Diffusion of Enhanced Recovery Principles in Gynecologic Oncology surgery: is active implementation still necessary? Gynecologic Oncology; 134(3):570-575.

Dickson E, Argenta PA, Reichert JA. (2012) Results of introducing a rapid recovery program for total abdominal hysterectomy. Gynecol Obstet Investig; 73:21-25.

Eberhart LHJ, Koch T, Ploger B, Wagner U, Wulf H, Zwiorek L, et al. (2008): enhanced recovery after major gynecological surgery for ovarian cancer-an objective and patient based assessment of a traditional versus a multimodal fast track rehabilitation programme.;49:180-94. 
Eva M, Smith M, Ahmed S. (2016) Implementation of enhanced recovery after surgery (ERAS) in gynecological oncology; Arch Gynecol Obstet; 294:137-143.

Gerardi MA, Santillan A, Meisner B, et al. (2008): a clinical pathway for patients undergoing primary cytoreductive surgery with rectosigmoid colectomy for advanced ovarian and primary peritoneal cancers. Gynecologic oncology; 108(2): 282-286. [PubMed: $18023851]$.

Gillinov AM, Davis EA, Alberg AJ, Rykiel M, Gardner TJ, Cameron DE. (1992) pulmonary embolism in the cardiac surgical patient. Ann Thorac Surg; 53:988-991.

Greco M, Capretti G, Beretta L, Gemma M, Pecorelli N, Braga M. (2014): Enhanced recovery program in colorectal surgery: a meta- analysis of randomized controlled trials. World journal of surgery; 38(6): 1531-1541.

Joshi GP and Ogunnaike Bo. (2005) Consequences of inadequate postoperative pain relief and chronic persistent postoperative pain. Anesthesiol Clin North America; 23:21-36.

Joshi P, Kulkarni S, Hunter C, Shahrour W, Surana S, Batra V .(2016) Are urologists getting French-fried? Discrepancy between the label advertised and actual sizes of endoscopic urological materials. Indian Journal of Urology, Vol 32, Supplement 1.

Kalogera E, Bakkum-Gamez JN, Jankowski CJ, Trabuco E, Lovely JK, Dhanorker S, et al. (2013): Enhanced Recovery in Gynecologic Surgery. ObstetGynecol; 122: 319-28.

Kehelt H, Wilmore DW. (2008) Evidence based surgical care and the evolution of fast-track surgery. Ann Surg; 248:189-98.

Kehlet H, Wilmore D. (2002): Multimodal strategies to improve surgical outcome. Am J Surg; 183:630-41.

Khan S, Wilson T, Ahmed J, Owais A, Macfie J. (2010) Quality of life and and patient satisfaction with enhanced recovery protocols. Colorectal Dis; 12: 1175-82.

Kinsman L, Rotter T, James E. (2010) what is a clinical pathway? Development of a definition to inform the debate. BMC Med; 8:31.

Kinsman L. (2004) Clinical pathway compliance and quality improvement. Nurs Stand;18:33-5. 
Lu D, Wang X, Shi G. (2012): Perioperative enhanced recovery programmes for gynecological cancer patients. The Cochrane database of systematic reviews; 12:CD008239.[Pubmed: 23235656].

Micieli G, Cavallini A, Quaglini S. (2002) Guideline compliance improves stroke outcome a preliminary study in 4 districts in the Italian region of Lombardia. Stroke; 33:1341-7. doi: 10.1161/01.STR.0000013663.27776.DB.

Minig L, Biffi R, Zanagnolo V. (2009): Reduction of postoperative complication rate with the use of early oral feeding in gynecologic oncologic patients undergoing a major surgery: a randomized controlled trial. Annals of surgical oncology; 16(11):3101-3110.

Modesitt Sc, Sarosiek Bm, Trowbridge Er, Redick Dl, Shah Pm, Thiele Rh, Tiouririne M, Hedrick Tl. (2016) Enhanced recovery implementation in major gynecologic surgeries: effect of care standardaization, Obstet Gynecol; 123:457-66.

Pruthi Rs, Chun J, Richman M. (2003). Reducing time to oral diet and hospital discharge in patients undergoing radical cystectomy using a perioperative care plan. Urology; 62:6615. 65-6. discussion-

Pruthi Rs, Nielsen M, Smith A, Et Al. (2010) Fast track program in patients undergoing radical cystectomy: results in 362 consecutive patients. J Am Coll Surg; 210:93-9.

Rajeswari T (2011): A study to assess patient's satisfaction with quality of nursing care. Diploma diss., Trivandrum.

Rello J, Lorente C, Bodí M, Diaz E, Ricart M, Kollef Mh. (2002) why do physicians not follow evidence-based guidelines for preventing ventilator-associated pneumonia? A survey based on the opinions of an international panel of intensivists. Chest; 122:656-61.

Rotter T, Kinsman L, James E, Machotta A, Gothe H, Willis J, Et Al. (2010) Clinical pathways: effects on professional practice, patient outcomes, length of stay and hospital costs. Cochrane Database Syst Rev; 3:3. - 
Samama Mm, Dahl Oe, Quinlan Dj, Mismetti P, Rosencher N. (2003) Quantification of risk factors for venous thromboembolism: a preliminary study for the development of a risk assessment tool. Haematologica; 88:1410-1421.

Seehusen Da. (2010) Clinical pathways: effects on practice, outcomes, and costs. Am Fam physician; 82:1338-9.

Smeltzer Sc, Bare Bg, Hinkle Jl, Et Al. (2010) Brunner \& Suddarth's textbook of medical-surgical nursing $12^{\text {th }}$ ed. Philadelphia: Wolters Kluwer/Lippincott Williams \& Wilkins.

Thiele Rh, Rea Km, Turrentine Fe, Friel Cm, Hassinger Te, Mcmurry Tl, Et Al. (2015): Standardization of care: impact of an enhanced recovery protocol on length of stay, complications, and direct costs after colorectal surgery. J AM CollSurg; 220: 430-43.

Thorell A, Nygren J, Ljungqvist O. (1999) Insulin resistance: a marker of surgical stress. Curr Opin Clin Nutr Metab Care; 2:69-78.

Verheijen Pm, Vdven Awh, Davids Php, Vd Wall Bjm, Pronk A (2012): Feasibility of enhanced recovery program in various patients groups. Int. J. Colorectal Dis; 27:507-11.

Vlug Ms, Bartels Sa, Wind J, Et Al (2012): Which fast track elements predict early recovery after colon cancer surgery? Colorectal disease: the official journal of the Association of Coloproctology of Great Britain and Ireland; 14(8):1001-1008. [PubMed: 21985079]

Wang Y. (2013) Effect of clinical pathway in caesarean operation. Med Innovation China; 10:2.

Wijik L, Franzen K, Ljungqvist O, Nilsson K. (2014) Implementing a structured enhanced recovery after surgery (ERAS) protocol reduces length of stay after abdominal hysterectomy. Acta Obstet Gynecol Scand; 93:749-756.

Wisely J, Barclay K. (2016) Effects of an Enhanced Recovery After Surgery programme on emergency surgical patients. ANZ J Surg ;86(11):883-888. 


\section{الطرق الإكلينيكية للرعاية التمريضية بعد العملية الجراحية للسيدات اللاتي يخضعن لعمليات أمراض النساء بمستثفيات بورسعيد}

\section{أ.د / سناءعلي نور- أ.م.د/ منار فتحى هيبةـ د/ السيدة حمدي نصر- حنان محمد علي أبو السادات}

أستاذ تمريض النساء و التوليد ـ كلية التمريض ـ جامعة الزقازيق ـ أستاذ مساعد تمريض الأمومة و النساء و التوليد ـ كلية

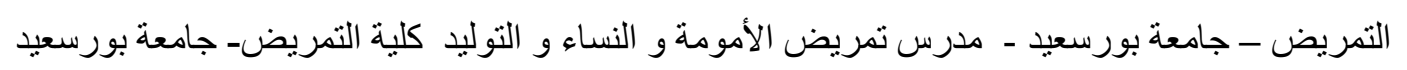

\section{الـخـلاصــة}

الطرق الإكلينيكية هى تدخل معقد لصنع القرار المتبادل وتنظيم عمليات الرعاية لمجمو عة محددة من المرضى خلال فترة محددة وقد أجريت هذه الدراسة شبه التجريبية لتحديد الآثار المترتبة للطرق الإكلينيكية للرعاية التمريضية بعد العطية الجراحية للمرضى الذين يخضعون لعمليات أمر اض النساء بمستشفي بورسعيد العام ،مستشفي بورفؤاد العام ومستشفي التضامن بمحافظة بورسعيد وقد إثنملت عينة البحث علي 112سيدة تم تقسيمها إلي مجمو عتين: المجمو عة الأولي (المجموعة الضابطة) تشتمل علي (56) من السيدات تم إعطائهن الرعاية التمريضية من المستشفي و المجموعة الثانية (مجموعة الدراسة) تشتمل علي (56) من السيدات تم إعطائهن الرعاية التمريضية الخاصة بالطرق الإكلينيكية .وقد تم تجميع البيانات عن طريق

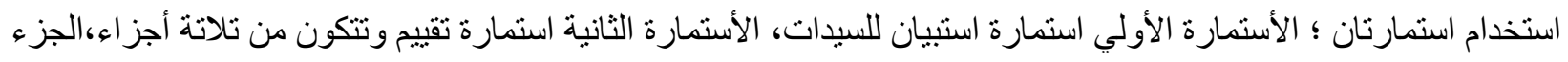
الأول ويشمل: الفحص البدنى والفحوصات قبل العملية والجزء الثاني ويشمل التطبيق العملي لخطوات الرعاية التمريضية الإعنيادية والخاصة بالطرق الإكلينيكية ، الجزء الثالث ويشمل النتائج الرئيسية بعد العملية الجراحية. وكثفت ونتائج هذه الدر اسة أن برنامج الطرق الإكلينيكية أدى إلى وجود فروق ذات دلالة إحصائية عن وجود تحسن و اضح في نتائج بعد العملية الجر احية ـ وأوصت الدر اسة بأنه يجب أن يطبق مفهوم الطرق الإكلينيكية في عمليات أمر اض النساء لتحسين نتائج المرضى إسى

$$
\text { و الحد من المضاعفات بعد العملية الجر احية. }
$$

الكلمات الإسترشادية : عمليات النساء ، الإدارة التمريضية للطرق الإكلينيكية. 